\title{
Detalles realistas para una guerra idealizada. Una aproximación a las Hazañas Bélicas de Boixcar
}

\author{
Juan José DíAz Benítez \\ Universidad de Las Palmas de Gran Canaria \\ jjdiaz@dch.ulpgc.es
}

Recibido: 2 de julio de 2014

Aceptado: 3 de septiembre de 2014

\section{Resumen}

Hazañas Bélicas ha sido estudiado por algunos de los principales especialistas en la historia del cómic español. Sin embargo, todavía quedan cuestiones pendientes de un estudio más detallado, como la diferenciación de las sucesivas ediciones de este cómic, la elección de conflictos en los que se desarrollan sus historias y la fascinación por la tecnología bélica. Este artículo analiza estos aspectos a través de una muestra de los cuadernos publicados entre 1950 y 1956. Entre sus principales conclusiones destacan la preferencia por la Segunda Guerra Mundial como marco para las historias, el predominio de héroes norteamericanos y alemanes y el detallismo de la representación de la tecnología bélica.

Palabras clave: cómic; propaganda; Segunda Guerra Mundial; Guerra Fría, franquismo.

\section{Realistic details for an idealized war. An approach to Hazañas Bélicas by Boixcar}

\begin{abstract}
Hazañas Bélicas has been studied by some of the main specialists on the history of the Spanish comics. However, there are questions that require a more detailed study, as the successive publish of this comic, the election of wars as contexts for the stories and the fascination on war technology. This article analyzes these subjects taking a selection of the comics published between 1950 and 1956. Among its main conclusions, it's to be noted the preference of the Second World War as context for the stories, the preeminence of American and German heroes and the minuteness of the representation of war technology.
\end{abstract}

Key words: comic; propaganda; Second World War; Cold War; francoism.

\section{Referencia normalizada}

Díaz Benítez, J. J. (2014) Detalles realistas para una guerra idealizada. Una aproximación a las Hazañas Bélicas de Boixcar. Historia y Comunicación Social. Vol. 19. Páginas 209-230.

Sumario: Introducción. 1. Una saga longeva. 2. El problema de las fuentes. 3. La "teoría de las tres guerras" en viñetas. 4. El despliegue de tecnología bélica. 5. Conclusiones. 6. Referencias bibliográficas. 


\section{Introducción}

La guerra ha sido uno de los acontecimientos que más se ha repetido a lo largo de la historia, hasta el punto de convertirse en una constante que requiere una aproximación estructural como proceso histórico con características propias. Así ha ocurrido con investigaciones como la de John Keegan (1990) sobre el miedo que experimenta el soldado en combate y los medios utilizados para superarlo, a través del estudio específico de casos en contextos tan diferentes como la Guerra de los Cien Años, las guerras napoleónicas y la I Guerra Mundial. Sin embargo, el hecho bélico no suele presentarse de forma objetiva, sino deformado por múltiples factores, entre los que destaca la propaganda de los beligerantes, bien para ensalzar los éxitos y fuerzas propias, bien para desacreditar al enemigo y minimizar sus logros. Así ha ocurrido con el conflicto más cruento de la historia, la Segunda Guerra Mundial, del cual se han elaborado imágenes alejadas de la realidad y que, no obstante, se han difundido más que esta última. En este sentido es preciso recordar que las películas norteamericanas rodadas durante la guerra, con una fuerte carga propagandística, constituían una de las principales fuentes de información sobre la contienda para la población civil de Estados Unidos e incluso para los soldados que todavía no habían entrado en combate con el enemigo (Curley, 1998: 241-242) (Shull y Wilt, 1996: 1-2). Por ello no es de extrañar que Paul Fussell, parafraseando a Walt Whitman, afirmara al respecto que "la guerra real nunca llegará a los libros" $(2003,359)$.

Esta visión distorsionada de la guerra se encuentra también en Hazañas Bélicas, quizá el cómic bélico que mayor impacto ha tenido en España y sobre el cual se ha escrito mucho, aunque no todo lo que había que decir. Todavía quedan cuestiones abiertas, como la identificación de las fuentes, objeto de análisis en los dos primeros apartados de este artículo, de los cuales uno está dedicado a las sucesivas series y reediciones de este cómic y el otro a las posibilidades y limitaciones que entraña el análisis de una de las reediciones más recientes y, por tanto, de más fácil acceso. A continuación habría que plantear el estudio detallado de una serie de aspectos que confieren originalidad a estos cuadernos de aventuras, sobre todo a los relatos escritos y dibujados por Guillermo Sánchez Boix, Boixcar, responsable de su éxito inicial. Se trata de la mitificación del combatiente, la imagen de la mujer, las connotaciones morales y religiosas, atípicas en este género, y el dibujo realista y documentado del armamento de la época. Son cuestiones sobre las que ya han escrito los investigadores que han estudiado estos relatos y que debido a su complejidad requieren una extensión que rebasa los límites de este trabajo. En consecuencia, su atención se centra en dos de ellas: la elección de los conflictos en los que están ambientados los relatos y la reproducción detallada de la tecnología bélica. El análisis de estos dos aspectos se desarrolla en el tercer y cuarto apartados, con el fin de demostrar una de las características que definen no sólo a este cómic sino también, de una u otra forma, al género bélico: la transmisión de un relato idealizado de la guerra bajo una apariencia de realismo. 


\section{Una saga longeva}

El cuaderno de aventuras de los años cuarenta y cincuenta no se distingue precisamente por su calidad, tanto en lo que se refiere al soporte en el que está impreso como a las tintas utilizadas y al contenido de la mayoría de ellos. La penuria de la España autárquica, el ínfimo poder adquisitivo del público infantil al que iba dirigido y la avidez de muchos editores influyeron en la baja calidad que caracteriza al cuaderno de aventuras de este periodo, tal y como han afirmado Pedro Porcel (2010: 109-112), Salvador Vázquez de Parga (1980: 40-43), Terenci Moix (2007: 161-170) y Antoni Guiral (2007: 130). Por ello no es de extrañar que no fuera un objeto destinado a perdurar y que, una vez pasadas aquellas décadas en las que eran intercambiados e incluso alquilados, terminaran desapareciendo. Hoy apenas se conserva una mínima fracción de los miles de ejemplares que inundaron el mercado español durante esos años hasta saturarlo, de modo que no es fácil encontrar unos cuadernos, antes infravalorados y que actualmente constituyen una fuente tan valiosa como difícil de localizar.

Cuadro 1. Ediciones y reediciones de Hazañas Bélicas, 1948-2014

\begin{tabular}{|c|c|c|c|}
\hline EDITORIAL & CONTENIDO & Núms. & PERIODO \\
\hline \multirow{10}{*}{ Ediciones Toray } & Primera serie & 29 & $1948-1949$ \\
\hline & Reedición de la primera serie en álbumes & 9 & $1949-1950$ \\
\hline & Segunda serie & 321 & $1950-1963$ \\
\hline & Almanaques & 16 & $1951-1966$ \\
\hline & Reedición de la segunda serie en álbumes & 1 & $1952-1952$ \\
\hline & Serie núm. extra (azul) & 371 & $1957-1971$ \\
\hline & Serie especial/núm. extra (rojo) & 328 & $1958-1971$ \\
\hline & Novelas gráficas & 252 & $1961-1971$ \\
\hline & $\begin{array}{l}\text { Reedición de los cuadernos de Boixcar en formato } \\
\text { vertical }\end{array}$ & 110 & $1965-1969$ \\
\hline & Novelas gráficas & 6 & $1972-1972$ \\
\hline \multirow{3}{*}{ Ediciones Ursus } & Reedición en formato vertical y apaisado & 190 & $1973-1988$ \\
\hline & "Gorila", en formato vertical & 17 & $1973-1973$ \\
\hline & "Gorila", en formato vertical & 8 & $1980-1980$ \\
\hline \multirow{2}{*}{ G 4 Ediciones } & Reedición de cuadernos apaisados de Toray & 25 & $1987-1990$ \\
\hline & Reedición de novelas gráficas de Toray & 21 & $1987-1989$ \\
\hline \multirow{2}{*}{ Fondos Editoriales } & $\begin{array}{l}\text { Reedición de los cuadernos apaisados de Hazañas } \\
\text { Bélicas }\end{array}$ & 18 & 1991-1996 \\
\hline & Reedición de los relatos de Johnny Comando y Gorila & 5 & $1992-1992$ \\
\hline \multirow{2}{*}{ Editores de Tebeos } & Selección de historietas dibujadas por Jordi Longarón & 1 & $2012-2012$ \\
\hline & Reedición de los relatos de Jonnny Comando y Gorila & 4 & $2013-\ldots$ \\
\hline Planeta DeAgostini & Reedición de la segunda serie & 75 & 2014 \\
\hline
\end{tabular}

Fuente: http://www.tebeosfera.com/obras/series/hazanas belicas boixcar 1949.html, consultado el 1 de agosto de 2013. Salvo que se indique lo contrario, la información sobre las ediciones y reediciones de Hazañas Bélicas procede de esta fuente. Elaboración propia. 
Hazañas Bélicas no es una excepción a este panorama, en el que, a las sucesivas ediciones iniciadas en 1948 y desarrolladas hasta principios de los setenta, es preciso añadir varias reediciones, mezcladas a veces con trabajos inéditos. Afortunadamente, la excelente base de datos confeccionada por el equipo de Tebeosfera permite clarificar este confuso panorama de miles de relatos publicados y repetidos a lo largo de más de sesenta años (Cuadro 1). La primera serie fue publicada por Ediciones Toray entre 1948 y 1949, después de que Boixcar se percatara de las posibilidades que ofrecía el género bélico tras la breve colección Episodios de guerra, de Jesús Blasco (Navarro, 1977: 26-27). Esta editorial nació en 1945, fruto de la colaboración entre Torrecilla y Ayné, prolongando su existencia durante más de un cuarto de siglo, con series de gran calidad a cargo de autores conocidos (Porcel, 2010: 152-153). La serie inicial no tuvo gran éxito, pero sí su reedición en álbumes en 1949 y 1950, lo cual llevó al inicio de una segunda serie a partir de este último año, con un total de 321 números de aparición quincenal. Esta periodicidad quincenal se confirma al menos hasta el número 121 extraordinario, titulado "El cerco de Leningrado", pues en la última viñeta de la página 10 del relato está inscrito el año 1955. Además de estos números, se suele incluir en esta serie 16 almanaques, cuya publicación se inició en 1951. Hubo un intento de reeditar la segunda serie en álbumes, como se había hecho con la primera, de los cuales se publicó al menos un volumen en 1952.

El éxito de la segunda serie condujo a otra de números extras, desarrollada entre 1957 y 1971, con la reedición de la segunda serie y la inclusión de nuevos relatos. Cada uno de los cuadernos de la tercera serie contenía, por término medio, tres relatos, ya fueran inéditos o reeditados, por lo que en total esta serie incluyó más de 1.000. Al año siguiente, Ediciones Toray sacó una serie especial de números extra, cuya ilustración de portada estaba enmarcada entre dos bandas rojas, mientras que la de 1957 lo hacía en bandas azules. La serie roja publicaba episodios inéditos, tres en los primeros 126 números y uno entre los números 127 y 160 . A partir del número 161 esta serie adoptó el formato de novela gráfica, con 36 páginas y se dedicó exclusivamente a las aventuras del sargento Gorila hasta acabar con el número 328.

Las cuatro series iniciadas entre 1948 y 1958 fueron publicadas en forma de cuadernos apaisados, formato que había consolidado a partir de 1934 la editorial Vecchi y utilizado por la historieta de aventuras de los años cuarenta y cincuenta (Guiral, 2007: 111-122). Dado el limitado número de autorizaciones para revistas, la mayoría de las colecciones de los años 40 se publicaban como folletos, es decir, publicaciones unitarias en las que no existía una continuidad aparente entre sus diferentes títulos. En este sentido, hubo una mayor tolerancia en la periodicidad a partir de enero de 1946, cuando el control de la prensa pasó al Ministerio de Educación (Martín, 2011: 95-99 y 115). La restricción afectó a la primera serie de Hazañas Bélicas, cuyas portadas dan la apariencia de un tratamiento unitario, en la que aparece el título de la serie, pero no el número del relato. La excepción al respecto es el último número de la serie, "Epopeya", en cuya portada se indica que es continuación del relato anterior "Alma de cántaro". La creación del Ministerio de Información y Turismo en 1951 permitió la regularización de numerosos cuadernos y revistas editados hasta entonces 
como folletos, lo cual condujo al incremento de las publicaciones, convertidas en un producto de ocio masivo (Porcel, 2011: 129-132). La regularización se aprecia en la segunda serie, ya numerada y cuyo título, Hazañas Bélicas, está resaltado dentro de un recuadro en la portada.

Las dos primeras series de Hazañas Bélicas comienzan en el periodo de auge del cuaderno de aventuras cuyo apogeo se sitúa en 1957-1962, cuando aparecen las dos siguientes series. Es en esta última etapa en la que Pedro Porcel sitúa el inicio del declive del cuaderno de aventuras, que tiende a desaparecer entre 1963 y 1966, en un contexto de cambio social y económico, en el que se imponen un nuevo modelo de héroe, que cuestionaba los valores tradicionales, y la competencia de la televisión, más barata, cómoda y atractiva que el cuaderno (Porcel, 2010: 316-319 y 396-399). La censura, más intensa paradójicamente en la década de los sesenta que en las anteriores, tal y como se aprecia en los trabajos de Salvador Vázquez de Parga (1980: 24-31) y Vicente Sanchis (2009), y la competencia de las historietas extranjeras también contribuyeron a este declive (Guiral, 2007: 157-159). No obstante, estas dos últimas series continuaron hasta principios de los años setenta, coexistiendo con la edición de Hazañas Bélicas en forma de novelas gráficas. El nuevo formato consistía en cuadernos verticales de 32 a 64 páginas, desde 1966 con el calificativo de "novelas gráficas para adultos", aunque el contenido continuaba estando dirigido al público juvenil (Vázquez de Parga, 1980: 31). Toray también llevó a cabo una reedición de los cuadernillos de Boixcar en 1965-1969, bajo el título de Boixcar. Obras completas, en formato novela gráfica. En esta reedición se supone que la periodicidad era semanal, aunque el periodo de cuatro años para un centenar de números sugiere que ésta fue quincenal.

En los años setenta y ochenta Ediciones Ursus prosiguió con la publicación de Hazañas Bélicas. La serie iniciada en 1973 experimentó grandes cambios de formato. En los primeros 47 números fue vertical y, a partir del número 48, apaisado. Los números 101-185 reprodujeron portadas de los años cincuenta en ventanas sobre fondo azul: hasta el número 161 se trataba de portadas de la segunda serie, mientras que los siguientes contenían portadas de la serie de 1957 y los dos últimos, 186 y 187, tenían portadas nuevas. La serie continuó hasta 1988, por lo que su periodicidad fue posiblemente mensual. Ursus también editó varios números de Gorila en formato vertical. En 1987, G 4 Ediciones S.A. lanzó dos reediciones de los relatos publicados por Toray en los años cincuenta y sesenta. La primera consistió en 24 números ordinarios y uno extraordinario, el almanaque de 1990, en formato apaisado, reeditados más tarde en cinco tomos con portadas de la edición de Ursus de 1973. La segunda consistía en 20 novelas gráficas y un almanaque para 1989, reeditadas después en siete tomos con portadas de Ursus. Apenas unos años más tarde, Fondos Editoriales S. L. reeditó 90 relatos de las aventuras de Johnny Comando y Gorila en cinco tomos, así como 352 episodios de Hazañas Bélicas en 18 tomos. Las últimas reediciones de esta obra han corrido a cargo de Editores de Tebeos en 2012, cuando publicó una recopilación de relatos dibujados por Jordi Longarón, y 2013, con la reedición de los 
relatos de Johnny Comando y Gorila, además de la reedición de la segunda serie por Planeta DeAgostini en 2014.

\section{El problema de las fuentes}

La sucesión de ediciones y reediciones durante más de sesenta años puede inducir a la confusión a la hora de estudiar esta obra, dada la mezcla de relatos de diferentes series en una misma reedición. Un ejemplo característico consiste en una de las reediciones más recientes, la llevada a cabo por Fondos Editoriales en 1991 y 1996. Se trata de una de las más extensas y fáciles de encontrar, en la que cabe distinguir dos conjuntos: los primeros diez tomos, publicados en 1991, con unas 3.000 páginas, y los ocho siguientes, impresos para Carbonell-Bartra S.L. en 1996, con 2.450 páginas y portadas en color. Los diez primeros tomos, impresos sin las correspondientes portadas, están pensados para el deleite del coleccionista o el aficionado a este cómic, pero no para el investigador, pues en ninguno de ellos se indica el número con el que fue publicado inicialmente cada relato ni la serie a la que pertenece. De este modo, cualquier estudio que se quiera hacer a partir de esta fuente debe comenzar por la identificación de los números y series que contiene.

La primera serie de Hazañas Bélicas está identificada completamente en Tebeosfera, por lo que no es difícil localizar dos de estos relatos en los tomos 3 y 7 de la reedición de 1991. La segunda está casi completa en dicha base de datos, pues sólo faltan los números extraordinarios 209, 221 y 229, correspondientes a "Vivimos todavía", "Hacia el ocaso" y "La muerte dijo no", aunque ninguno de los tres figura en la reedición de 1991. En total hay 117 números de la segunda serie, concentrados en los siete primeros tomos. Estos relatos se corresponden, de forma incompleta, con los números 4-157, los cuales aparecen normalmente ordenados, aunque con la algún número de la serie azul intercalado entre ellos. A veces la identificación plantea dudas, concretamente en "Fugados del infierno", título que aparece en el número 71 de la serie de 1950 y el 27 de la serie de 1957: su extensión limitada a ocho páginas, la inadecuación del contenido a la portada de la serie de 1950 y el hecho de no estar dibujado por Boixcar hacen pensar que se trata del relato de la serie de 1957.

El resto consiste en relatos de la serie azul de 1957, predominantes en los cuatro últimos tomos, junto con algunos relatos que pueden proceder de los almanaques iniciados con la segunda serie, como "Historia de un par de botas", "Dos fantasmas", "Uno contra mil" y "Un buen soldado", los dos últimos de 6 y 5 páginas, respectivamente. La serie azul es más difícil de reconstruir a partir de Tebeosfera, debido a las lagunas existentes. No obstante, a partir de los cuadernos de segunda mano en venta es posible identificar los escasos relatos de esta reedición que no aparecen en la citada base de datos: "La vergüenza de un cobarde" (núm. 68), "Medallas para un cobarde" (núm. 170), "Corazones en guerra" (núm. 120), "Su última oportunidad” (núm. 172) y "Hacia el caos" (núm. 181). 
La identificación del periodo en el que fueron publicados los relatos no es una cuestión baladí. La aparición de relatos inéditos se prolongó a lo largo de un cuarto de siglo, aproximadamente, junto con las primeras reediciones. Un lapso de tiempo tan amplio hace pensar en matices e incluso diferencias entre los primeros cuadernos y las últimas novelas gráficas, al menos en la medida en que la España de principios de los setenta no era la misma que la de finales de los cuarenta. Sería un error, por tanto, analizar los relatos independientemente del contexto en el que aparecieron por primera vez o considerar, sin más, que las novelas gráficas de principios de los setenta son iguales en contenido y forma a los cuadernos editados durante el primer franquismo. En este sentido, es preciso prestar especial atención a los relatos de la segunda serie reeditados en 1991, cuya aparición por primera vez ha de situarse entre 1950 y 1956, años de gran importancia para la política exterior española y la supervivencia de la dictadura franquista. Se trata del periodo cuyo comienzo coincide con el inicio de las negociaciones hispano-norteamericanas que condujeron a los pactos de 1953 y que culminó a finales de 1955 con la entrada de España en la ONU, superando así el aislamiento al que el régimen había sido condenado tras la Segunda Guerra Mundial. Todo ello en el marco de una creciente influencia norteamericana y un marcado anticomunismo, perfectamente visibles en Hazañas Bélicas.

Pero al analizar esta obra es preciso considerar también otro aspecto no menos importante: la autoría. El éxito de esta saga se debe en buena medida a las historias escritas e ilustradas por Boixcar en las tres primeras series, las cuales se distinguen del resto por su calidad artística, la gravedad que impone a los guiones y el providencialismo presente habitualmente en sus relatos. Boixcar dibujó la primera serie, pero a partir del número 172 de la segunda contó con la ayuda de su hermano Josep María, el cual la continuó desde el número 257. Después intervinieron Vicente Farrés, con guiones de Alex Simmons, y Alan Doyer, este último de forma habitual desde el número 280 (Conde Martín, 1977: 23). Boixcar también participó en la serie azul de 1957, lo suficiente para que aún el número 179, "Dos cruces en Bastogne", llevara su firma. En más de una ocasión las historias no están firmadas, pero en ellas se percibe el estilo de Boixcar, con tramas para resaltar el armamento y crear un ambiente dramático, así como las viñetas que ocupan dos tercios de la página y reproducen alguna escena de combate o máquinas de guerras. Algunos de los guiones no eran suyos, sino enviados por los lectores al concurso convocado por la revista, como "Una barba de sargento", "Bajo el cielo de Corea" y "Visiones de pesadilla" en el tercer tomo o "Patrulla al amanecer" en el segundo. No obstante y dado que son el producto de un concurso convocado por la propia revista, se sitúan en la misma línea que los escritos por Boixcar y, por tanto, deben ser tenidos en cuenta al analizar la segunda serie. En total, la edición de 1991 incluye 117 relatos de esta serie, lo cual representa el 74 '5\% de los 157 primeros números. Considerado el conjunto de los 321 números que componen la serie, la proporción que representa este centenar de relatos se reduce al $36^{\prime} 4 \%$. Por tanto, los resultados del estudio de estos relatos no pretenden ser definitivos para el conjunto de la serie, pero sí constituyen una aproximación razonable para los cuadernos de Hazañas Bélicas publicados en un periodo tan interesante para la política exterior española como es el de 1950-1956, 
cuya influencia se percibe claramente en la elección de los conflictos en los que se enmarcan los relatos de este periodo.

\section{La "teoría de las tres guerras" en viñetas}

Los cuadernos de aventuras de los años cuarenta y cincuenta suelen representar de un modo maniqueo la lucha entre el bien el mal, en la que los villanos son vencidos por unos héroes provistos de todas las virtudes humanamente posibles y que prescinden de los poderes sobrenaturales de los superhéroes norteamericanos (Vázquez de Parga, 1980: 74-77). Hazañas Bélicas no es una excepción al respecto, aunque con la particularidad de que este esquema es aplicado a unos relatos ambientados en un contexto muy reciente, como la Segunda Guerra Mundial, o incluso coetáneo, en el caso de los conflictos de la Guerra Fría. Tal proximidad cronológica implicaba que las historietas no podían sustraerse a la visión oficial que el régimen franquista daba de estas guerras, lo cual influía notablemente en la caracterización de los beligerantes como héroes o villanos.

Un elemento fundamental de esta visión es la denominada "teoría de las tres guerras". Después de ayudar al Eje durante los primeros años del conflicto, incumpliendo reiteradamente las obligaciones de España como neutral, Franco declaró al embajador norteamericano Carlton J. H. Hayes, en la visita que éste le hizo el 29 de julio de 1943, que en aquel momento existían tres guerras. Una de ellas, entre Alemania y los aliados anglosajones, ante la que el Gobierno español era neutral. Otra, entre Estados Unidos y Japón, en la que España se posicionaba más próxima a los norteamericanos. La tercera, contra el comunismo, en la que España intervenía al lado de los alemanes. Esta "teoría de las tres guerras" no era más que un intento de justificar su discutible neutralidad, en un momento en el que el curso de la guerra se decantaba del lado de los Aliados y estos aumentaban su presión sobre el régimen franquista (Gil Pecharromán, 2008: 108-110). No tuvo ninguna influencia en el embajador norteamericano, pero el discurso anticomunista fue agitado vehementemente por la dictadura para superar el aislamiento en la posguerra, aprovechando el contexto de la Guerra Fría, lo cual se materializó finalmente en los pactos hispano-norteamericanos de 1953 (Viñas, 2012: 301-321).

No es de extrañar, por tanto, que la mayoría de los investigadores que han analizado los relatos de Boixcar coincidan en señalar alguna o varias de las siguientes características: una germanofilia fuera de lo habitual en el cómic de aquellos años, la influencia norteamericana, la deshumanización de los combatientes japoneses y la demonización del comunismo, personificado por soviéticos, chinos y norcoreanos. Así se puede constatar en los trabajos de Luis Conde Martín (1977: 24-25), Antonio Marimon Riutort (2005: 121-137), Joan Navarro (1991: tomo I, sin numerar), Pedro Porcel (2010: 210-215), Antoni Segarra (1977: 27-28) y Salvador Vázquez de Parga (1980: 120-126). Una aproximación estadística, con las limitaciones ya indicadas 
en el apartado anterior, permite confirmar y matizar estas afirmaciones. Con cierta frecuencia los relatos están ambientados en más de un escenario, por lo que el Cuadro 2 especifica cuántos de ellos se refieren a más de un conflicto, mientras que el Cuadro 3 distingue entre aquellos que se desarrollan en un solo frente (1) y los que lo hacen en dos (0'5). Destaca sobre todo el predominio de la Segunda Guerra Mundial como escenario, pues los conflictos ambientados total o parcialmente en ella suponen más de dos tercios del total, mientras que los situados en la Guerra Fría representan menos de un tercio y aquellos localizados exclusivamente en la I Guerra Mundial se limitan a uno (Cuadro 2).

Cuadro 2. Conflictos en los que están ambientados los relatos de Hazañas Bélicas, 1950-1956

\begin{tabular}{|c|c|c|c|c|c|c|}
\hline TOMO & $\begin{array}{c}\text { PRIMERA } \\
\text { GUERRA } \\
\text { MUNDIAL }\end{array}$ & $\begin{array}{c}\text { PRIMERA- } \\
\text { SEGUNDA } \\
\text { GUERRA } \\
\text { MUNDIAL }\end{array}$ & $\begin{array}{c}\text { SEGUNDA } \\
\text { GUERRA } \\
\text { MUNDIAL }\end{array}$ & $\begin{array}{l}\text { SEGUNDA } \\
\text { GUERRA } \\
\text { MUNDIAL- } \\
\text { GUERRA } \\
\text { FRÍA }\end{array}$ & $\begin{array}{c}\text { GUERRA } \\
\text { FRÍA }\end{array}$ & TOTAL \\
\hline 1 & --- & 1 & 14 & --- & 3 & 18 \\
\hline 2 & --- & 1 & 17 & --- & --- & 18 \\
\hline 3 & $\overline{---}$ & 1 & 16 & 1 & 1 & 19 \\
\hline 4 & --- & --- & 9 & --- & 8 & 17 \\
\hline 5 & --- & --- & 4 & 1 & 12 & 17 \\
\hline 6 & 1 & --- & 9 & 1 & 8 & 19 \\
\hline 7 & --- & --- & 5 & --- & 4 & 9 \\
\hline Total & 1 & 3 & 74 & 3 & 36 & 117 \\
\hline$\%$ & $0 ’ 85$ & $2 ’ 56$ & 63'25 & 2'56 & $30 ’ 77$ & 100 \\
\hline
\end{tabular}

Fuente: VV.AA.: Hazañas Bélicas, Barcelona, tomos 1-7. Elaboración propia.

En el caso de la Segunda Guerra Mundial (Cuadro 3), lo más frecuente es que las historias se sitúen en el marco de la lucha entre los aliados occidentales y el III Reich, ya sea en Europa occidental (incluidos los relatos de la Primera Guerra Mundial), el Mediterráneo o el norte de África. No obstante, si sumamos los relatos enmarcados en el frente ruso con los de la Guerra Fría podremos apreciar cómo predomina claramente el enfrentamiento contra el comunismo, ya sea protagonizado por soldados alemanes durante la Segunda Guerra Mundial o norteamericanos después de 1945, sobre todo en Corea. De hecho, más de la mitad de las historias que se desarrollan durante la Guerra Fría se refieren a la Guerra de Corea, mientras que las referidas a Indochina y la Europa ocupada se reducen sólo a cinco en cada caso. Otros escenarios de la lucha anticomunista durante la posguerra representados en este cómic son la guerra civil china, Birmania, Pakistán antes de la descolonización británica y el Japón ocupado. 
Cuadro 3. Principales escenarios de la Segunda Guerra Mundial en Hazañas Bélicas, 1950-1956

\begin{tabular}{|c|c|c|c|c|}
\hline TOMO & $\begin{array}{c}\text { EUROPA OCCIDENTAL } \\
\text { Y NORTE DE ÁFRICA }\end{array}$ & $\begin{array}{c}\text { FRENTE } \\
\text { ORIENTAL }\end{array}$ & $\begin{array}{c}\text { SUDESTE ASIÁTICO } \\
\text { Y PACÍFICO }\end{array}$ & TOTAL \\
\hline 1 & $5^{\prime} 0$ & $3^{\prime} 0$ & $6^{\prime} 5$ & $14^{\prime} 5$ \\
\hline 2 & $1^{\prime} 5$ & $4^{\prime} 0$ & $2^{\prime} 5$ & $18^{\prime} 0$ \\
\hline 3 & $9^{\prime} 5$ & $5^{\prime} 0$ & $2^{\prime} 5$ & $1^{\prime} 0$ \\
\hline 4 & $4^{\prime} 5$ & $2^{\prime} 5$ & $2^{\prime} 0$ & $9^{\prime} 0$ \\
\hline 5 & $5^{\prime} 5$ & --- & $0^{\prime} 5$ & $6^{\prime} 0$ \\
\hline 6 & $3^{\prime} 5$ & $6^{\prime} 0$ & $1^{\prime} 0$ & $10^{\prime} 5$ \\
\hline 7 & $3^{\prime} 0$ & $1^{\prime} 0$ & $1^{\prime} 0$ & $5^{\prime} 0$ \\
\hline Total & $42^{\prime} 5$ & $21^{\prime} 5$ & $16^{\prime} 0$ & $80^{\prime} 0$ \\
\hline$\%$ & $53^{\prime} 1$ & $26^{\prime} 9$ & $20^{\prime} 0$ & 100 \\
\hline
\end{tabular}

Fuente: VV.AA.: Hazañas Bélicas, tomos 1-7. Elaboración propia.

La preferencia por uno u otro escenario influye en la elección de los héroes, que no siempre coincide con lo dicho hasta ahora. Las historias ambientadas en el frente occidental, el Mediterráneo o el norte de África no muestran una especial preferencia por el combatiente alemán sino por los Aliados, los cuales protagonizan aproximadamente dos tercios de estos relatos, mientras que los alemanes sólo realizan esta función en solitario en poco más del $21 \%$, porcentaje que aumenta a más del $32 \%$ si se incluye las historias en las que comparten protagonismo con británicos y norteamericanos. En cualquier caso, destaca el mayor peso de los héroes británicos en estos escenarios, que con más de un $41 \%$ se sitúan a gran distancia de norteamericanos y alemanes, así como la presencia casi anecdótica de los franceses, limitada a un episodio (Cuadro 4).

Cuadro 4. Protagonistas de los relatos ambientados total o parcialmente en Europa occidental y norte de África durante la Segunda Guerra Mundial en Hazañas Bélicas, 1950-1956

\begin{tabular}{|c|c|c|c|c|c|c|c|}
\hline TOMO & ALEM. & NORTEAM. & BRIT. & FRAN. & $\begin{array}{c}\text { BRIT. Y } \\
\text { ALEM. }\end{array}$ & $\begin{array}{c}\text { NORTEAM. Y } \\
\text { ALEM. }\end{array}$ & TOTAL \\
\hline 1 & 1 & -- & 3 & --- & 1 & --- & 5 \\
\hline 2 & 5 & 4 & 2 & --- & --- & 2 & 13 \\
\hline 3 & --- & 3 & 5 & 1 & --- & 1 & 10 \\
\hline 4 & 2 & 1 & 2 & --- & --- & --- & 5 \\
\hline 5 & -- & 2 & 3 & --- & 1 & --- & 6 \\
\hline 6 & 2 & 1 & 1 & --- & --- & --- & 4 \\
\hline 7 & --- & --- & 3 & --- & --- & --- & 3 \\
\hline Total & 10 & 11 & 19 & 1 & 2 & 3 & 46 \\
\hline$\%$ & $21 ' 74$ & $23^{\prime} 91$ & $41 ' 30$ & $2 ' 17$ & $4 ' 35$ & 6 '52 & 100 \\
\hline
\end{tabular}

Fuente: VV.AA.: Hazañas Bélicas, tomos 1-7. Elaboración propia. 
No se trata de héroes planos, sino enfrentados a dilemas morales, en los que suele prevalecer el bien, aunque sea a costa del protagonista, y siempre es castigado el mal. En este sentido y tal y como han señalado Pedro Porcel (2010: 212-215), Antoni Marimon Riutort (2005: 121-125), Antonio Altarriba (2001: 270-273) y Luis Conde (1977: 24-25), no se aprecia una actitud crítica contra el nazismo o el militarismo alemán, ni siquiera contra el Holocausto, a pesar de alguna alusión ocasional a los campos de concentración en "Espíritu de sacrificio" y "Tierra quemada". Simplemente, el soldado alemán aparece representado como un patriota, al igual que norteamericanos y británicos.

No obstante, al cambiar de escenario sí se ve con mayor nitidez la preferencia por alemanes y norteamericanos. Las historias ambientadas en el frente oriental no ofrecen dudas al respecto, pues en ellas los protagonistas son alemanes o, en su defecto, españoles, como ocurre en las tres protagonizadas por la División Azul: "Vista, suerte y al toro", "Sinfonía en rojo y azul" y "El cerco de Leningrado". Las excepciones al respecto son escasas. Por un lado, "Hombres de hielo", en el que el protagonista alemán se deja llevar por la avaricia, convirtiéndose en un ser tan cuestionable como su antagonista soviético, un ladrón que ha robado oro de las iglesias polacas. Ante este panorama, el único modelo de conducta correcto está personificado por la hija del ladrón, la cual, gracias a su actitud compasiva, logra acabar con vida el episodio. Por el otro, "Iván el rojo", un piloto soviético que, ante la crueldad de los guerrilleros comunistas, reniega de su ideología y termina combatiendo en el bando alemán. En suma, dos excepciones que no contradicen la norma de presentar la guerra en el frente oriental como un conflicto entre el bien, encarnado por las fuerzas alemanas, y el mal, identificado con las tropas soviéticas.

Más tajante aún es la distinción entre buenos y malos en el sudeste asiático y el Pacífico, donde los japoneses nunca son los buenos, papel reservado exclusivamente a los Aliados, que casi siempre son norteamericanos. Apenas cabe destacar como excepción "Soldado del cielo", en el que el protagonismo es compartido por un piloto norteamericano y un misionero español, y "A bombazo limpio", cuyo héroe es un joven birmano que ayuda a los chindits, los comandos británicos infiltrados tras la líneas japonesas, y que termina auto-inmolándose para ayudarles a liberar su aldea.

En conjunto, el protagonismo norteamericano en los relatos de la Segunda Guerra Mundial no es tan frecuente como el alemán, debido a la mayor frecuencia con la que aparece el frente ruso que el Pacífico como escenario, pero al sumar las historias situadas ambientadas en la Guerra Fría, el héroe norteamericano es el más representativo en estos relatos de Boixcar. En los diferentes conflictos de la posguerra, los norteamericanos son tres de cada cuatro protagonistas, lo cual no es de extrañar, dado que la contienda más utilizada para ambientar las historias de este periodo es la Guerra de Corea (Cuadro 5). No siempre los héroes "norteamericanos" son de Estados Unidos, pues incluyen también cubanos enrolados en sus Fuerzas Armadas. Así sucede con el soldado Fulgencio, cuyo nombre recuerda al dictador cubano Batista, que en 1952 se había hecho con el poder en la isla, en "Sueños de gloria" o con el piloto Rafael Bravo en "Rutas rojas". 
Cuadro 5. Protagonistas de los relatos ambientados total o parcialmente en la Guerra Fría en Hazañas Bélicas, 1950-1956

\begin{tabular}{|c|c|c|c|c|c|c|}
\hline TOMO & NORTEAM. & FRANC. & ALEM. & SOV. & OTROS & TOTAL \\
\hline 1 & 4 & --- & --- & --- & --- & 4 \\
\hline 2 & --- & --- & --- & --- & --- & --- \\
\hline 3 & 1 & --- & --- & --- & --- & 2 \\
\hline 4 & 7 & --- & --- & 1 & --- & 8 \\
\hline 5 & 11 & --- & --- & 1 & --- & 12 \\
\hline 6 & 4 & 4 & --- & --- & 1 & 9 \\
\hline 7 & 3 & 1 & --- & --- & --- & 4 \\
\hline Total & 30 & 5 & 1 & 2 & 1 & 39 \\
\hline$\%$ & $76 ' 92$ & $12 ' 82$ & $2 ' 56$ & $5 ' 13$ & $2 ' 56$ & 100 \\
\hline
\end{tabular}

Fuente: VV.AA.: Hazañas Bélicas, tomos 1-7. Elaboración propia.

A gran distancia aparece la Guerra de Indochina, con cinco episodios protagonizados por soldados franceses, aunque en uno de ellos el protagonismo es compartido por tres legionarios: un francés, un alemán y un español. Tampoco falta un relato con prisioneros alemanes, capturados durante la Segunda Guerra Mundial, que escapan del cautiverio soviético a principios de los cincuenta, ni una historia en la que el héroe es un soldado surcoreano, aparentemente inofensivo, que se convierte en una auténtica máquina de matar para salvar a un capellán norteamericano. Incluso uno de los héroes norteamericanos se convierte en chino, gracias a una habilidosa operación de cirugía estética, se enamora de una enfermera china y rechaza la posibilidad de recuperar su aspecto occidental. Al igual que en el frente oriental durante la Segunda Guerra Mundial, en la Europa de la posguerra es posible encontrar héroes rusos, siempre y cuando sean anticomunistas. Así ocurre con el comandante que huye de la URSS junto con su madre, después de encontrarla y conocer cómo fue vilmente separado de ella durante la revolución de 1917. También es el caso del capitán curtido en el campo de batalla, que ayuda a los resistentes cristianos de un país bajo la ocupación soviética.

\section{El despliegue de tecnología bélica}

Una de las características que definen el estilo artístico de Boixcar es el dibujo realista que reproduce minuciosamente las armas empleadas en la Segunda Guerra Mundial y en la Guerra de Corea, resaltadas por el uso de tramas y grandes viñetas, que confieren un especial atractivo a estas historias. Estas características han sido destacadas por los principales investigadores del cuaderno de aventuras de la posguerra, como Antonio Altarriba (2001: 268-270), Luis Conde Martín (1977: 25-26), Antoni Marimon Riutort (2005: 119), Terenci Moix (2007: 226-227) y Pedro Porcel (2010: 215-217). La fascinación por la tecnología bélica se aprecia también en las ocupaciones más frecuentes de los protagonistas, militares en su inmensa mayoría y 
que en más de un $81 \%$ consisten en soldados del Ejército de Tierra o en aviadores, lo cual permite al autor explayarse en los dos tipos de máquinas de guerra que reproduce con mayor frecuencia y detalle: aviones y carros de combate (Cuadro 6).

Cuadro 6. Ocupaciones de los protagonistas de los relatos de Hazañas Bélicas, 1950-1956

\begin{tabular}{|c|c|c|c|c|c|c|c|c|}
\hline \multirow{2}{*}{ TOMO } & \multicolumn{5}{|c|}{ EJÉRCITO } & \multirow{2}{*}{ ESPÍA } & \multirow{2}{*}{ CIVIL } & \multirow{2}{*}{ TOTAL } \\
\cline { 2 - 8 } & TIERRA & AIRE & MAR & $\begin{array}{c}\text { MAR/ } \\
\text { AIRE }\end{array}$ & $\begin{array}{c}\text { TIERRA/ } \\
\text { AIRE }\end{array}$ & & & \\
\hline 1 & 7 & 6 & 2 & --- & --- & --- & 3 & 18 \\
\hline 2 & 9 & 5 & 2 & 1 & --- & 1 & --- & 18 \\
\hline 3 & 14 & 3 & 1 & --- & --- & --- & 1 & 19 \\
\hline 4 & 9 & 4 & 1 & --- & 1 & 1 & 1 & 17 \\
\hline 5 & 10 & 3 & 1 & --- & 1 & 2 & --- & 17 \\
\hline 6 & 13 & 2 & 1 & --- & --- & 2 & 1 & 19 \\
\hline 7 & 4 & 4 & --- & --- & --- & 1 & --- & 9 \\
\hline TOTAL & 66 & 27 & 6 & 1 & 2 & 7 & 6 & 117 \\
\hline$\%$ & $56^{\prime} 41$ & $23^{\prime} 08$ & $6{ }^{\prime} 84$ & $0{ }^{\prime} 85$ & $1{ }^{\prime} 71$ & $5{ }^{\prime} 98$ & $5{ }^{\prime} 13$ & $1000^{\prime} 00$ \\
\hline
\end{tabular}

Fuente: VV.AA.: Hazañas Bélicas, tomos 1-7. Elaboración propia.

Aparentemente resulta sorprendente la reducida presencia de la Marina, un ejército más tecnificado que el de Tierra, aunque la explicación puede deberse a la mayor dificultad para distinguir modelos concretos. Los tipos de barcos, ya sean portaaviones, destructores, submarinos, lanchas de desembarco, cargueros, etc., se diferencian con claridad, pero no los modelos dentro de cada uno de ellos, algo que estaría al alcance de cualquier marino profesional, pero no de todo el público aficionado a estos relatos. Así, los submarinos alemanes de "Submarinos en el Atlántico" y "Abismos mortales", claramente del tipo VIIA, son parecidos al japonés de "Hiroshima, hora cero" y, en menor medida, al soviético de "Titanes bajo el mar", quizá de la clase K. 
Cuadro 7. Aviones y armas aéreas alemanas y japonesas de la Segunda Guerra Mundial en Hazañas Bélicas, 1950-1956

\begin{tabular}{|c|c|c|c|}
\hline NACIONALIDAD & MODELO & TIPO & RELATO \\
\hline \multirow{21}{*}{ Alemana } & $\mathrm{Me}-323$ & Transporte & \multirow{5}{*}{ "El cielo en llamas" } \\
\hline & Ju-90 & Transporte & \\
\hline & Fw-190 & Caza & \\
\hline & He-112 & Caza & \\
\hline & $\mathrm{Bv}-222$ & Hidroavión & \\
\hline & Bf-109 & Caza & \multirow{4}{*}{ "La ruta de la muerte } \\
\hline & Bf-110 & Caza & \\
\hline & Ju- 88 & Bombardero & \\
\hline & Do-217 & Bombardero & \\
\hline & Fw-187 & Caza & \multirow{3}{*}{ "El capitán Valor" } \\
\hline & He-111 & Bombardero & \\
\hline & Ar-196 & Hidroavión & \\
\hline & Ju-87 Stuka & Bombardero en picado & \multirow{2}{*}{ "La sima azul" } \\
\hline & Do-26 & Hidroavión & \\
\hline & Bf-410 & Caza & "Dos valientes" \\
\hline & $\mathrm{Bv}-138$ & Hidroavión & "Huellas de sangre" \\
\hline & Ju-52 & Transporte & "Lluvia de metralla" \\
\hline & Bf-262 & Caza & "El precio de la gloria" \\
\hline & He-111Z & Bombardero & "Infiernos volantes" \\
\hline & $\mathrm{V}-1$ & Bomba volante & "I a murte circo", \\
\hline & $\mathrm{V}-2$ & Misil & "La muerte ciega" \\
\hline \multirow{3}{*}{ Japonesa } & G-4M Betty & Bombardero & \multirow{2}{*}{ "Sangre en el Pacífico" } \\
\hline & Zero & Caza & \\
\hline & Okha & Bomba tripulada & "El héroe de Okinawa" \\
\hline
\end{tabular}

Fuente: VV.AA.: Hazañas Bélicas, tomos 1-7. Elaboración propia. 
Cuadro 8. Aeronaves británicas, norteamericanas y soviéticas de la Segunda Guerra Mundial en Hazañas Bélicas, 1950-1956

\begin{tabular}{|c|c|c|c|}
\hline NACIONALIDAD & MODELO & TIPO & RELATO \\
\hline \multirow{11}{*}{ Británica } & Lancaster & Bombardero & \multirow{4}{*}{ "Valientes con alas" } \\
\hline & Halifax & Bombardero & \\
\hline & Stirling & Bombardero & \\
\hline & Spitfire & Caza & \\
\hline & Wellington & Bombardero & "Titanes del cielo" \\
\hline & Typhoon & Cazabombardero & \multirow{2}{*}{ "La muerte ciega" } \\
\hline & Stirling & Bombardero & \\
\hline & Mosquito & Bombardero & "Hombres rana" \\
\hline & Hurricane & Caza & "El capitán Valor" \\
\hline & Hampden & Bombardero & "Dos valientes" \\
\hline & Sunderland & Hidroavión & \multirow{2}{*}{ "Espíritu de sacrificio" } \\
\hline \multirow{9}{*}{ Norteamericana } & Catalina & Hidroavión & \\
\hline & B-17 & Bombardero & \multirow{2}{*}{ "Una cruz en Monte Cassino" } \\
\hline & P-47 Thunderbolt & Caza & \\
\hline & F4-F Wildcat & Caza & \multirow{2}{*}{ "Sangre en el Pacífico" } \\
\hline & B-26 Marauder & Bombardero & \\
\hline & SBD Dauntless & Bombardero en picado & \multirow{3}{*}{ "Titanes del cielo" } \\
\hline & TBF Avenger & Torpedero & \\
\hline & R-5 & Helicóptero & \\
\hline & P-38 Lightining & Caza & "Soldado del cielo" \\
\hline \multirow{5}{*}{ Soviética } & Mig-3 & Caza & \multirow{2}{*}{ "Estelas de muerte" } \\
\hline & $\mathrm{I}-16$ & Caza & \\
\hline & Yak & Caza & "El rugido de la fiera" \\
\hline & Tupolev SB & Bombardero & \multirow{2}{*}{ "Cazadores de monstruos" } \\
\hline & Tupolev Tu-2 & Bombardero & \\
\hline
\end{tabular}

Fuente: VV.AA.: Hazañas Bélicas, tomos 1-7. Elaboración propia.

La relación de armas representadas en Hazañas Bélicas es muy amplia, destacando por su variedad las aeronaves: al menos 19 modelos de aviones alemanes, 11 británicos, nueve norteamericanos, cinco soviéticos y dos japoneses (Cuadros 7 y 8). Un total de 46 aeronaves, sin contar la bomba volante V-1, el misil V-2 o la bomba tripulada Okha y a las que hay que añadir tres modelos de aviones de la Gran Guerra en "Semillas de odio", concretamente los cazas biplanos De Havilland DH-9 y Fokker y el bombardero biplano Gotha. A veces muestra armas que, pese a su rareza, fueron reales, como el bombardero doble He-111Z y el fusil de asalto StG-44 con cañón curvo y periscopio. El arsenal alemán (Cuadro 9) incluye armas de diferente procedencia: el Feldkanon 288 era en realidad uno de los modelos soviéticos de 76 '2 mm capturados en grandes cantidades, mientras que el cañón de 149/35 modelo 1910 era italiano. 
Cuadro 9. Vehículos y armas terrestres alemanas y japonesas de la Segunda Guerra Mundial en Hazañas Bélicas, 1950-1956

\begin{tabular}{|c|c|c|c|}
\hline NACIONALIDAD & MODELO & TIPO & RELATO \\
\hline \multirow{21}{*}{ Alemana } & Panzer I & Carro de combate & \multirow{2}{*}{ "Más duros que el acero" } \\
\hline & Panzer III & Carro de combate & \\
\hline & Panzer II & Carro de combate & "Vista, suerte y al toro" \\
\hline & Panzer IV & Carro de combate & \multirow{4}{*}{ “Bill el Pacífico" } \\
\hline & Mod. 1910 (italiano) & Cañón de campaña & \\
\hline & Feldkanon 288 (ruso) & Cañón de campaña & \\
\hline & Pak $36 / 36$ & Cañón contra-carro & \\
\hline & Panzer VI Tiger & Carro de combate & "O todo o nada" \\
\hline & StuG III & $\begin{array}{l}\text { Cañón de asalto } \\
\text { autopropulsado }\end{array}$ & "El precio de la gloria" \\
\hline & SIG-33 & $\begin{array}{l}\text { Cañón de infantería } \\
\text { autopropulsado }\end{array}$ & \multirow[t]{2}{*}{ "El señor Bazooka" } \\
\hline & StG-44 & Fusil de asalto & \\
\hline & Sd. Kfz. 233 & Semioruga & \multirow[b]{2}{*}{ "Visiones de pesadilla" } \\
\hline & Sd. Kfz. 250 & $\begin{array}{l}\text { Vehículo de } \\
\text { reconocimiento }\end{array}$ & \\
\hline & Sd. Kfz. 2 & Semioruga & $\begin{array}{c}\text { "Una cruz en Monte } \\
\text { Cassino" }\end{array}$ \\
\hline & Goliath & $\begin{array}{l}\text { Vehículo de demolición } \\
\text { por control remoto }\end{array}$ & "Barro ruso" \\
\hline & FH-18 & $\begin{array}{l}\text { Obús de campaña } \\
\text { remolcado }\end{array}$ & \multirow[t]{2}{*}{ "El rugido de la fiera" } \\
\hline & Nebelwerfer & Lanzacohetes & \\
\hline & Flak 36 & Cañón antiaéreo & \multirow{3}{*}{ "Suerte negra" } \\
\hline & Kubelwagen & Vehículo ligero & \\
\hline & MP-40 & Subfusil & \\
\hline & MG-42 & Ametralladora & "Iván el rojo" \\
\hline \multirow[b]{2}{*}{ Japonesa } & Tipo 89 & Carro de combate & "Terremoto" \\
\hline & Tipo 95 & Carro de combate & "Manchas rojas en la isla" \\
\hline
\end{tabular}

Fuente: VV.AA.: Hazañas Bélicas, tomos 1-7. Elaboración propia. 
Cuadro 10. Vehículos y armas terrestres aliadas de la Segunda Guerra Mundial en Hazañas Bélicas, 1950-1956

\begin{tabular}{|c|c|c|c|}
\hline NACIONALIDAD & MODELO & TIPO & $\begin{array}{l}\text { RELATO EN EL QUE } \\
\text { APARECE }\end{array}$ \\
\hline \multirow{8}{*}{ Británica } & Valentine II & Carro de combate & \multirow{4}{*}{$\begin{array}{l}\text { "El hombre que tuvo } \\
\text { miedo" }\end{array}$} \\
\hline & Matilda & Carro de combate & \\
\hline & Bren Carrier & Blindado ligero & \\
\hline & Beaverette Mk. III & $\begin{array}{c}\text { Vehículo de } \\
\text { reconocimiento blindado }\end{array}$ & \\
\hline & Churchill & Carro de combate & \multirow{2}{*}{ "Bill el Pacífico" } \\
\hline & PIAT & Fusil antitanque & \\
\hline & Humber Scout Car & $\begin{array}{l}\text { Vehículo de } \\
\text { reconocimiento blindado }\end{array}$ & $\begin{array}{c}\text { "Los diablos de la } \\
\text { noche" }\end{array}$ \\
\hline & Mk II / Mk III & Cañón pesado & \multirow{2}{*}{ "Tierra quemada" } \\
\hline Francesa & Char B1 & Carro de combate & \\
\hline \multirow{7}{*}{ Norteamericana } & Bazooka & Lanzagranadas & \multirow{3}{*}{ "O todo o nada" } \\
\hline & M-3 & Cañón contra-carro & \\
\hline & Jeep & Vehículo todoterreno & \\
\hline & M-4 Sherman & Carro de combate & \multirow{3}{*}{ "Tierra quemada" } \\
\hline & $\mathrm{T}-30$ & Obús autopropulsado & \\
\hline & $\mathrm{M}-10$ & Cazatanques & \\
\hline & Thompson M-1928 & Subfusil & "Suerte negra" \\
\hline \multirow{6}{*}{ Soviética } & T-34 & Carro de combate & \multirow{2}{*}{ "El rugido de la fiera" } \\
\hline & BT-5 & Carro de combate & \\
\hline & Maxim & Ametralladora & "Iván el rojo" \\
\hline & SU-100 & Cazatanques & “4 camaradas" \\
\hline & Modelo 1943 & Cañón de campaña & "El precio de la gloria" \\
\hline & $\mathrm{KV}-2$ & Carro de combate & $\begin{array}{c}\text { "Vista, suerte y al } \\
\text { toro" }\end{array}$ \\
\hline
\end{tabular}

Fuente: VV.AA.: Hazañas Bélicas, tomos 1-7. Elaboración propia.

Muchas veces, sobre todo en el caso de los aviones, suele indicar el modelo representado, aunque a veces la identificación es errónea, como ocurre con el carro de combate KV-2, confundido con el IS-2 Iosef Stalin (Cuadro 10). No siempre es fácil identificar el arma representada: el cañón antiaéreo de $88 \mathrm{~mm}$ de "Suerte negra" puede ser el Flak 36 o su antecesor el Flak 18. No obstante, los resultados de la tarea de documentación de Boixcar se reflejan nítidamente en el cómic, donde reproduce algunas fotografías históricas. "Manchas rojas en la isla" contiene una viñeta en la página 184 que es una reproducción de la foto "Sticks and Stones", tomada por William Eugene Smith durante la batalla de Iwo Jima, en la que se desarrolla el relato. "Terremoto" incluye en la página 100 una viñeta que reproduce una foto del avance japonés hacia Manila en 1942. 
Cuadro 11. Armas norteamericanas y soviéticas de la Guerra Fría en Hazañas Bélicas, 1950-1956

\begin{tabular}{|c|c|c|c|}
\hline NACIONALIDAD & MODELO & TIPO & $\begin{array}{c}\text { RELATO EN EL QUE } \\
\text { APARECE }\end{array}$ \\
\hline \multirow{24}{*}{ Norteamericana } & $\mathrm{C}-47$ & Transporte & \multirow{5}{*}{ "Locos del aire" } \\
\hline & P-51 Mustang & Caza & \\
\hline & F-85 & Caza a reacción & \\
\hline & F-86 & Caza a reacción & \\
\hline & Sikorsky H03S & Helicóptero & \\
\hline & B-24 Liberator & Bombardero & "Arrozales de muerte" \\
\hline & F-80 & Caza a reacción & \multirow{4}{*}{ "Rutas rojas" } \\
\hline & Dragonfly & Avioneta & \\
\hline & M-41 Walker bulldog & Carro de combate & \\
\hline & Napalm & Líquido inflamable & \\
\hline & P-80 & Caza a reacción & \multirow{2}{*}{ "Slim el Bravo" } \\
\hline & T-6 Texan & Apoyo táctico & \\
\hline & Sikorsky XR-6 & Helicóptero & "La cota de los espectros" \\
\hline & Sikorsky R-4 & Helicóptero & "El Paralelo 38" \\
\hline & XP-84 Thunderjet & Caza a reacción & "Desafío a la muerte" \\
\hline & Fairchild C-82 & Transporte & \multirow{2}{*}{ "La guerra del átomo" } \\
\hline & Sikorsky S-55 & Helicóptero & \\
\hline & M-3 Stuart & Carro de combate & $\begin{array}{l}\text { "La odisea de un } \\
\text { blindado" }\end{array}$ \\
\hline & M-24 Chaffee & Carro de combate & "Almas en lucha" \\
\hline & M-26 Pershing & Carro de combate & "El veterano" \\
\hline & M-8 Greyhound & $\begin{array}{c}\text { Vehículo de } \\
\text { reconocimiento blindado }\end{array}$ & "Bajo el cielo" \\
\hline & F-6 & Caza a reacción & \multirow{3}{*}{ "40 banderas" } \\
\hline & Ilyushin Il-28 & Bombardero & \\
\hline & Mig-15 & Caza a reacción & \\
\hline Soviética & BA-64 & Blindado sobre ruedas & "Torbellinos de fuego" \\
\hline
\end{tabular}

Fuente: VV.AA.: Hazañas Bélicas, tomos 1-7. Elaboración propia.

Las historias de la Guerra Fría no ofrecen una variedad de armas y vehículos tan amplia como la Segunda Guerra Mundial, pero tampoco es desdeñable (Cuadro 11). "40 banderas" muestra dos aviones a reacción soviéticos de la época: el bombardero Ilyushin Il-28 y el caza Mig-15, este último repetido frecuentemente en los relatos ambientados en estos años. Pero lo más impresionante en estos relatos es la gran variedad de aviones norteamericanos, similar a la de la Luftwaffe. En total, un mínimo de 16 aeronaves, más otras ya citadas en la Segunda Guerra Mundial, como el P-47 Tunderbolt y la superfortaleza volante B-29. No falta incluso el napalm, ya empleado en la Segunda Guerra Mundial. A todo ello es preciso añadir el armamento terrestre, en el que destacan los carros de combate ligeros, como el entonces ya obso- 
leto M-3 Stuart en "La odisea de un blindado", el M-24 Chaffee en "Almas en lucha" y el novedoso, en 1951, M-41 Walker Bulldog en "Rutas rojas", además del carro de combate pesado M-26 Pershing en "El veterano".

Tampoco faltan los blindados tripulados por fuerzas comunistas, como el carro de combate T-34, en este caso norcoreano y ya citado en el frente ruso durante la Segunda Guerra Mundial. No obstante, la representación de blindados manejados por soldados chinos en la Guerra de Corea, como el BA-64 en "Torbellinos de fuego" y lo que parece ser un vehículo de reconocimiento blindado sobre ruedas M-8 Greyhound en "Bajo el cielo de Corea", responde más a las exigencias del guión que al rigor histórico. Los blindados son coetáneos de aquel conflicto y no es descartable que ya estuvieran en servicio con el ejército chino, pero probablemente no los usó en grandes cantidades en el conflicto coreano, si es que llegó a desplegarlos allí. En realidad, las divisiones chinas que protagonizaron la ofensiva del invierno de 1950-1951 contra las tropas de las Naciones Unidas estaban compuestas por infantería ligera, la cual se adaptó muy bien al abrupto terreno del norte de la península coreana, aunque también padeció graves carencias logísticas (Halberstam, 2009: 491-492, 530-533, 592 у 672-678).

En estas páginas se identifican más de 120 armas y vehículos representados por Boxicar, además de otras no mencionadas aquí, de lo cual se deduce una gran labor de documentación previa que distingue a Hazañas Bélicas de otros cuadernos de aventuras. Sin embargo, esto no quiere decir que Boixcar fuera siempre tan preciso, pues en sus relatos también podemos encontrar anacronismos y máquinas que parecen más bien un producto de la imaginación. Uno de los anacronismos más frecuentes consiste en la artillería "soviética", que tanto en "El cerco de Leningrado" como en "Monstruos en la estepa" son obuses franceses Schneider de $155 \mathrm{~mm}$ modelo 1917, aunque en el segundo relato están provistos de ruedas más parecidas a las usadas por los soviéticos. Lo mismo ocurre en "El soldado loco" con la artillería de campaña "soviética", en realidad cañones alemanes Krupp C. 96nA de 77 mm, e incluso con la artillería pesada "alemana" en "Bill el Pacífico", que consiste en cañones italianos de $149 \mathrm{~mm}$ modelo 1910. Estos tres modelos fueron utilizados en la Guerra Civil Española, por lo que Boixcar pudo recurrir a ellos para solucionar las lagunas que tuviera al respecto.

En otros casos, el armamento utilizado realmente en un determinado escenario aparece en manos del bando contrario, como la ametralladora alemana MG-42 manejada por soldados soviéticos en "Sinfonía en rojo y azul", situación que pudo darse en realidad, el hidroavión británico Sunderland pilotado por aviadores comunistas durante la Guerra de Corea en "Tempestad de almas", algo que difícilmente pudo ocurrir, o el caza comunista de la guerra de Indochina en "A tiro limpio", lo cual no llegó a suceder. En la misma línea se sitúa el carro de combate británico Centurion que aparece en "Dos vidas", un relato ambientado en la guerra de Indochina. A veces la aeronave mostrada es anacrónica, como el helicóptero Sikorsky S-55 de 1949, mostrado en "La guerra del átomo", un relato ambientado en la Alemania ocupada 
de 1945, o el caza soviético I-16 de "Cazadores de monstruos", representado en la Batalla de Berlín en 1945, cuando había dejado de volar en 1942.

\section{Conclusiones}

Analizar un cómic cuya trayectoria se dilata a lo largo de varias décadas y sucesivas series desborda las limitadas páginas de un artículo y tropieza con importantes dificultades a la hora de localizar e identificar las fuentes necesarias. Sin embargo, es posible realizar una aproximación a una muestra de la segunda serie, especialmente para la primera mitad de los 50, de gran importancia para la rehabilitación internacional de la dictadura franquista. No en vano, la identificación de héroes y villanos en los relatos de Hazañas Bélicas se corresponde con la denominada "teoría de las tres guerras", especialmente en lo que se refiere al anticomunismo. Si la elección de los protagonistas no debía contradecir a la ideología oficial, su credibilidad tenía que ir acompañada de un dibujo detallado y documentado que hiciera más creíble estas historias. Pese a algunos anacronismos, el trabajo de documentación de Boixcar está avalado por la identificación de un centenar de aeronaves y vehículos, sin contar piezas de artillería, buques, armas de infantería y otro equipamiento militar. Este detallismo confiere una apariencia de realismo a los relatos de Hazañas Bélicas, al crear una conexión con las imágenes de la Segunda Guerra Mundial y la Guerra de Corea, entre otros conflictos, que recibían los lectores.

Pero es sólo una apariencia que envuelve unos relatos idealizados que no pretenden mostrar la guerra en toda su crudeza. Como ha señalado Pedro Porcel, muchas veces da la impresión de que más que un cómic bélico se trata de relatos de enseñanza moral o religiosa ambientados en un contexto bélico (Porcel, 2010: 210-212). Unos relatos que reducen la guerra a una serie de consideraciones morales, frecuentemente de carácter personal y en los que el bien triunfa, mientras que aquellos que se dejan arrastrar por el mal fracasan. Un relato idealizado que como afirmaba Paul Fussell para el caso de la Segunda Guerra Mundial no tiene nada que ver con la experiencia bélica, ni siquiera con la del propio Boixcar en la Guerra Civil. Así, lejos de las miserias de una "guerra de pobres" (Semprún, 2004: 311) en comparación con la Segunda Guerra Mundial y marcada por una mayor pérdida de vidas por la represión en la retaguardia que por los combates en el frente, Boixcar puede ambientar sus historias en guerras muy próximas cronológicamente, pero ajenas a la experiencia de la mayoría de sus lectores, que buscan precisamente en el cómic de aventuras una evasión de la dura posguerra que estaban viviendo. Por eso el autor puede desarrollar en sus historias su fascinación por la tecnología y el derroche de medios de todo tipo en conflictos bélicos como la Segunda Guerra Mundial o la Guerra de Corea, en los que, a diferencia de la Guerra Civil, parece prevalecer la rectitud de los principios patrióticos y religiosos, justamente recompensada por la Providencia. 


\section{Referencias bibliográficas}

ALTARRIBA, A. (2001). La España del Tebeo. La Historieta Española de 1940 a 2000. Madrid: Espasa.

CONDE MARTÍN, L. (1977). "Presentación". En: "Dossier: Años Cincuenta. «Hazañas Bélicas»,”. En: Bang! Información y estudios sobre la historieta, $\mathrm{n}^{\circ} 13$, Barcelona: Martín Editor, p. 23-26.

CURLEY, S. (1998). "The War and Film in the United States and Britain". En: LEE, L. E. (ed.) (1998). World War II in Asia \& the Pacific \& the War's Aftermath, with General Themis: a Handbook of Literature \& Research. Westport: Greenwood Publishing Group, p. 241-254.

FUSSELL, P. (2003). Tiempo de guerra. Conciencia y engaño en la Segunda Guerra Mundial. Madrid: Turner.

GIL PECHARROMÁN, J. (2008). La politica exterior del Franquismo. Entre Hendaya y el Aaiún. Barcelona: Ediciones Flor del Viento.

GUIRAL, A. (coord.) (2007). Del tebeo al manga: una historia de los cómics. Tomo 7: El cuaderno popular: viñetas de género. Barcelona: Panini.

HALBERSTAM, D. (2009). La guerra olvidada. Historia de la guerra de Corea. Barcelona: Crítica.

KEEGAN, J. (1990). El rostro de la batalla. Madrid: Servicio de Publicaciones del Estado Mayor del Ejército.

MARIMON RIUTORT, A. (2005). Guerrers, corsaris, soldats i detectius. Els tebeos d'aventures sota el franquisme. Història i politica en el comic realista entre 1939 i 1975. Palma de Mallorca: Edicions Documenta Balear.

MARTÍN, A. (2011). "La historieta española de 1900 a 1951". En: Arbor, no 2, Madrid: CSIC, p. 63-128.

MOIX, T. (2007). Historia social del cómic. Barcelona: Bruguera.

NAVARRO, J. (1977). "Entrevista con Josep Ma Sánchez Boix". En: "Dossier: Años Cincuenta. «Hazañas Bélicas»,". En: Bang! Información y estudios sobre la historieta, $\mathrm{n}^{\mathrm{o}}$ 13, Barcelona: Martín Editor, p. 26-27.

PORCEL, P. (2011). "La historieta española de 1951 a 1970". En: Arbor, no 2, Madrid: CSIC, p. 129-158.

PORCEL, P. (2010). Tragados por el Abismo. La Historieta de Aventuras en España. Alicante: Edicions de Ponent.

SANCHIS, V. (2009). Franco contra Flash Gordon. La censura franquista aplicada a las publicacions infantils i juvenils (1936-1977). Valencia: Tres i Quatre S.L.

SEGARRA, A. (1977). "Análisis de «Hazañas Bélicas»". En: "Dossier: Años Cincuenta. «Hazañas Bélicas»,". En: Bang! Información y estudios sobre la historieta, $\mathrm{n}^{\circ}$ 13, Barcelona: Martín Editor, p. 27-28.

SEMPRÚN, J. (2004). Del Hacho al Pirineo. El Ejército Nacional en la Guerra de España. Madrid: Actas.

SHULL, M. S.; WILT, D. E. (1996). Hollywood War Films, 1937-1945. An Exhaustive Filmography of American Feature-Length Motion Pictures Relating to World War II. Jefferson (North Carolina) \& London: McFarland \& Company Inc. Publishers. 
VÁZQUEZ DE PARGA, S. (1980). Los cómics del franquismo. Barcelona: Editorial Planeta.

VIÑAS, A. (2012). "Centinela de Occidente". En: SEGURA, A.; MAYAYO, A.; ABELLÓ, T. (dirs.). La dictadura franquista. La institucionalització d'un règim. Barcelona: Universitat de Barcelona, p. 301-321.

VV.AA. (1991). Hazañas Bélicas. Barcelona: Fondos Editoriales S.L., tomos 1-10.

\section{El autor}

Juan José Díaz Benítez es Profesor contratado doctor del Departamento de Ciencias Históricas de la Universidad de Las Palmas de Gran Canaria. Sus investigaciones se centran en la política exterior española y el papel internacional de Canarias, especialmente durante la Segunda Guerra Mundial. Entre sus publicaciones destacan el libro Canarias indefensa (2008) y los artículos "The Italian Naval War in the Mid-Atlantic: Blockade Runners and Submarines in the Canary Islands (1940-1943)" (The Mariner's Mirror, $\mathrm{n}^{\circ}$ 100/2, 2014) y "Propaganda bélica en la gran pantalla: la incursión de Makin (1942) a través de la película Gung Ho!" (Historia Actual Online, $\left.\mathrm{n}^{\mathrm{o}} 31,2013\right)$. 